\title{
Ensino e aprendizagem da graduação em Odontologia: a percepção de estudantes sobre o cuidado humanizado em uma instituição de ensino odontológico
}

\author{
Teaching and learning of undergraduate Dentistry: students' perception of humanized care in a \\ dental education institution
}

Enseñanza y aprendizaje de la Odontología de pregrado: percepción de los estudiantes sobre el cuidado humanizado en una institución de educación odontológica

Recebido: 21/09/2021 | Revisado: 29/09/2021 | Aceito: 02/10/2021 | Publicado: 04/10/2021

\author{
Rafaela Reis da Silva \\ ORCID: https://orcid.org/0000-0001-6435-9942 \\ Universidade Federal de Minas Gerais, Brasil \\ E-mail: rafaelareissilva@gmail.com \\ Rosa Núbia Vieira de Moura \\ ORCID: https://orcid.org/0000-0002-8947-2797 \\ Universidade Federal de Minas Gerais, Brasil \\ E-mail: nubiamoura@ufmg.br \\ Viviane Elisângela Gomes \\ ORCID: https://orcid.org/0000-0001-9637-1911 \\ Universidade Federal de Minas Gerais, Brasil \\ E-mail: vivigomes_br@yahoo.com.br \\ Efigênia Ferreira e Ferreira \\ ORCID: https://orcid.org/0000-0002-0665-211X \\ Universidade Federal de Minas Gerais, Brasil \\ E-mail: efigeniaf@gmail.com
}

\begin{abstract}
Resumo
O presente estudo buscou, por meio de uma pesquisa qualitativa compreender a percepção da humanização, entre estudantes de Odontologia, no cuidado odontológico, nas clínicas de ensino de uma universidade pública da região Sudeste do Brasil. Entre as técnicas de produção de dados, optou-se pelo grupo focal, com o intuito de promover uma discussão participativa do tema do estudo. Participaram desta pesquisa seis estudantes, de diferentes faixas etárias e períodos. Em relação ao período, os participantes estavam entre o primeiro e oitavo período do curso de Odontologia. Dois participantes estavam nos períodos iniciais, tendo experenciado visitas na Unidade Básica de Saúde e quatro estudantes estavam nos períodos com vivência clínica e maior contato com o paciente. Como suporte teórico para a elaboração do roteiro, utilizaram-se das diretrizes da Política Nacional de Humanização. Os achados foram interpretados segundo a análise de conteúdo, com base no Interacionismo Simbólico, que busca compreender a relação dos grupos sociais com a conduta humana em sua relação cotidiana. Após interpretação emergiram três temas: Percepção da humanização; Humanização e Ensino e Direito dos usuários. É importante, nos cursos de graduação em Odontologia, que o ensino da humanização seja contemplado de forma transversal, para fazer as aproximações teóricas, com uma visão que extrapole a compreensão do ser humano de forma coletiva e individual no processo da integralidade do cuidado.
\end{abstract}

Palavras-chave: Humanização da assistência; Ensino superior; Assistência integral à saúde; Pesquisa qualitativa.

\begin{abstract}
The present study sought, through a qualitative research, to understand the perception of humanization, among dentistry students, in dental care, in teaching clinics of a public university in the Southeast region of Brazil. Among the data production techniques, the focus group was chosen, in order to promote a participatory discussion of the study topic. Six students participated in this research, from different age groups and periods. Regarding the period, the participants were between the first and eighth period of the Dentistry course. Two participants were in the initial periods, having experienced visits to the Basic Health Unit and four students were in the periods with clinical experience and greater contact with the patient. As theoretical support for the elaboration of the script, the guidelines of the National Humanization Policy were used. The findings were interpreted according to content analysis, based on Symbolic Interactionism, which seeks to understand the relationship of social groups with human conduct in their daily relationship. After interpretation, three themes emerged: Perception of humanization; Humanization and Teaching and Users' Rights. It is important, in undergraduate courses in Dentistry, that the teaching of humanization is
\end{abstract}


covered in a transversal way, in order to make theoretical approaches, with a vision that goes beyond the understanding of the human being collectively and individually in the process of comprehensive care.

Keywords: Humanization of assistance; Education, higher; Comprehensive health care; Qualitative research.

\section{Resumen}

El presente estudio buscó, mediante de una investigación cualitativa, comprender la percepción de humanización, entre estudiantes de Odontología, en la atención odontológica, en clínicas docentes de una universidad pública en la región sureste de Brasil. Entre las técnicas de producción de datos, se eligió el grupo focal, con el fin de promover una discusión participativa del tema de estudio. En esta investigación participaron seis estudiantes, de diferentes grupos de edad y períodos. En cuanto al período, los participantes se encontraban entre el primer y el octavo período del curso de Odontología. Dos participantes se encontraban en los períodos iniciales, habiendo experimentado visitas a la Unidad Básica de Salud y cuatro estudiantes se encontraban en los períodos con experiencia clínica y mayor contacto con el paciente. Como soporte teórico para la elaboración del guión se utilizaron los lineamientos de la Política Nacional de Humanización. Los hallazgos fueron interpretados según el análisis de contenido, basado en el Interaccionismo Simbólico, que busca comprender la relación de los grupos sociales con la conducta humana en su relación diaria. Después de la interpretación, surgieron tres temas: Percepción de la humanización; Humanización y Docencia y Derechos de los Usuarios. Es importante, en las carreras de grado en Odontología, que la enseñanza de la humanización se cubra de manera transversal, con el fin de realizar aproximaciones teóricas, con una visión que trascienda la comprensión del ser humano de manera colectiva e individual en el proceso de atención integral.

Palabras clave: Humanización de la atención; Educación superior; Atención integral de salus; Investigación cualitativa.

\section{Introdução}

A humanização é um tema que vem ganhando destaque pela necessidade de reafirmar que a prática assistencial seja contemplada na integralidade e não apenas nas necessidades fisiológicas (Terra et al., 2018). Este conceito vem sendo bastante discutido na literatura cientifica nos últimos anos, expondo uma grande preocupação para o atendimento humanizado em saúde (Benevides \& Passos, 2005; Rios, 2009; Moreira et al, 2015; Fuente-Martos et al., 2018). Em uma visão panorâmica, humanizar o atendimento é mais do que se preocupar com questões do atendimento clínico, implica na compreensão das angústias e incertezas do indivíduo, dando-lhe apoio e atenção efetiva na busca da solução de seu problema (Sueiras et al., 2017; Moreira et al., 2015). Como forma de apresentar dimensões fundamentais para ser aplicada em todos os serviços de saúde, o Ministério da Saúde lançou em 2004, a Política Nacional de Humanização (PNH). Como política a humanização deve traduzir os princípios e modos de operar os conjuntos das relações estabelecidas no processo do cuidado em saúde: profissional-paciente, entre os diferentes profissionais, as instâncias que organizam o SUS, as unidades e os serviços de saúde (Brasil, 2004).

O termo humanização é um "conjunto de estratégias para a qualificação da atenção, gestão e produção da saúde com o objetivo de aumentar o grau de corresponsabilidade dos diferentes atores que constituem o Sistema Único de Saúde (SUS)'(Brasil, 2012). Humanizar a atenção e a gestão em saúde requer aspectos como acesso com acolhimento, escuta qualificada, atenção integral, corresponsabilidade, democratização, controle social e, valorização dos trabalhadores e usuários (Brasil, 2004). Embora a humanização em saúde tenha sido (e por vezes ainda é) interpretada como proporcionar um ambiente mais agradável e este atributo se constitua em melhorias físicas do serviço, humanizar não se restringe a isto. Um atendimento humanizado envolve relações estabelecidas entre profissional-paciente, elencadas no respeito à dignidade da pessoa humana, na gestão compartilhada dos serviços e na política pública. Isso destaca que não é simplesmente tratar a doença ou os sintomas, a humanização convida os atores a experimentarem a cogestão como um dispositivo para gerar novos modos de gerir e cuidar (Moreira et al., 2015; Busch et al., 2019).

Diante de vários desafios o ensino da Odontologia, ao longo da história, foi marcado por grandes transformações. Nas últimas décadas, tem sido uma das grandes preocupações, construir uma formação comprometida com a sociedade. Com base no rigor técnico-científico, é meta na formação desse profissional, desenvolver habilidades que o possibilitem valorizar os sujeitos dentro do contexto socioeconômico e cultural, respeitando os valores, costumes e hábitos (Forte et al., 2015; Lage et 
al., 2017; Emmi, Silva \& Barrosos, 2018). Nesse contexto, as Diretrizes Curriculares Nacionais (DCN) para os cursos superiores são documentos que auxiliam a organização e articulação das propostas pedagógicas para as instituições de ensino superior. Na construção e organização dos seus programas elas servem de base para elaboração do Projeto Político Pedagógico (PPP). De acordo com as DCN, o perfil do egresso do curso de graduação em Odontologia deverá incluir características para uma formação generalista, humanístico e ético, crítico e reflexivo, para atuar em todos os níveis de atenção à saúde da população, tendo como base a compreensão da realidade social. Assim como, estar apto à atuação em equipe, de forma interprofissional, interdisciplinar e transdisciplinar (Brasil, 2002; Brasil, 2021).

O ensino odontológico concentra grande parte de sua carga horária no atendimento clínico, com o objetivo de formação e treinamento prático dos estudantes. No ensino da Odontologia, professores e estudantes precisam desenvolver competências e habilidades para atuar na assistência integral à saúde (Queiroz \& Dourado, 2009; Lage et al., 2017). No entanto, cabe questionar que muitas vezes, o reconhecimento da legítima demanda do usuário é desconsiderado, em função da preocupação com os aspectos técnicos da formação (Scalioni, Alves, Matos \& Ribeiro, 2008; Puplaksis, Silva, Nobili \& Ramos, 2010). Apesar de prevista a inclusão dos preceitos éticos para solucionar as demandas de saúde dos usuários, isto nem sempre acontece. Por isso, a importância de ressaltar que o tema humanização seja contemplado na formação profissional de forma transversal, englobando a conscientização e o aprendizado (Rios, 2009).

Destacamos que a temática sobre a formação profissional com o perfil humanístico torna-se protagonista a partir da publicação da nova DCN Resolução No 3, de 21 de junho de 2021, para os cursos de graduação em Odontologia. Destaca-se que os cursos em funcionamento terão o prazo de até dois anos, a partir da data de publicação, para aplicação das suas determinações às novas turmas abertas após o início da sua vigência. A nova DCN evidência em vários pontos que a graduação em Odontologia visa formar profissionais com relação a atenção à saúde para promover a humanização do cuidado. Desta forma ressaltamos o Art. $17^{\circ}$, que diz "A estrutura curricular do curso de graduação em Odontologia deverá levar em consideração as necessidades de saúde dos usuários e das populações, incluindo as dimensões ética, humanística e social, orientadas para a cidadania e para os direitos humanos, tendo as Ciências Humanas e Sociais como eixo transversal de formação. " (Brasil, 2021). Há um reconhecimento da necessidade de trabalhar o perfil humanístico de forma transversal para gerar mudança no ensino, para formar profissionais capazes a responder às necessidades sociais colocando o sujeito como protagonista da sua própria saúde.

O presente estudo buscou, por meio de uma pesquisa qualitativa compreender a percepção da humanização, entre estudantes de Odontologia, no cuidado odontológico, nas clínicas de ensino de uma Universidade pública da região Sudeste do Brasil.

\section{Metodologia}

O método qualitativo de pesquisa é aquele que se ocupa do nível subjetivo e relacional da realidade social. Este método foi escolhido por ser tratado por meio da história, do universo, dos significados, dos motivos, das crenças, dos valores e das atitudes dos atores sociais, por isso a riqueza de detalhes e conteúdo. Trata-se de uma estratégia para compreender a percepção das narrativas com um forte fator humanístico, interacional e empático (Minayo, 2013; González, 2020). É uma metodologia que facilita a compreensão dos eventos considerando as experiências de vida das pessoas. A narração do trabalho foi referida de acordo com os critérios consolidados para relato de pesquisa qualitativa (COREQ) (Souza, Marziale, Silva \& Nascimento, 2021).

Esta pesquisa teve interesse pelo conceito da humanização e os possíveis significados mediante o contexto em que os estudantes estão inseridos, nas situações cotidianas do ensino da graduação em Odontologia, assumindo como referencial teórico a Política Nacional de Humanização. Entre as técnicas de produção de dados, optou-se pelo grupo focal, com o intuito 
de promover uma discussão participativa do tema do estudo, com os participantes reunidos em um mesmo local e durante um certo período (Trad, 2009; Souza et al., 2019). Essa metodologia permite originar discussões e trocar experiências sobre as opiniões entre os participantes, potencializando a produção dos resultados da pesquisa (Trad, 2009).

O delineamento do estudo aconteceu em duas fases: (I) fase preparatória: o estudo piloto e; (II) fase de coleta de dados: grupo focal para o estudo principal. Na fase piloto, um pesquisador com experiência no uso dessa metodologia de pesquisa, conduziu o grupo focal com cinco estudantes, com a presença do pesquisador principal, a fim de testar e avaliar a compreensão da pergunta norteadora e explorar o roteiro, e se necessário realizar ajustes. Estas falas não foram incluídas no estudo.

Após esta fase, foi realizado o treinamento do pesquisador principal como moderador, para realização do grupo focal da pesquisa. Uma discussão prévia foi realizada, a fim de alinhar a rotina de trabalho, a forma de abordagem dos participantes, a leitura do Termo de Consentimento Livre e Esclarecido (TCLE), condução e moderação da conversa. Esse processo foi liderado por um pesquisador com experiência neste tipo de pesquisa.

$\mathrm{Na}$ etapa coleta de dados, o grupo focal com os estudantes foi conduzido pelo moderador e um observador, problematizando o tema humanização. A seleção dos participantes foi realizada de forma intencional, com o agendamento prévio da data e horário para realização. Os estudantes foram individualmente escolhidos para que pudessem contribuir de forma positiva para o diálogo no grupo focal. No sentido de proporcionar a adequação necessária (conforto, silêncio, tranquilidade) para coleta dos dados, utilizou-se sala especialmente cedida para este fim. A organização ocorreu uma hora antes do início do grupo focal, deixando as cadeiras na disposição de círculo, sobre cada uma, duas vias do TCLE. Foram utilizados dois gravadores Sony®, um posicionado no centro do grupo focal e outro sobre a mesa do observador, tendo sido testados previamente.

Como suporte teórico para a elaboração do roteiro, utilizaram-se das diretrizes da Política Nacional de Humanização. Foram selecionadas três dimensões, as mais imbricadas no momento do atendimento: acolhimento (reconhecer como legítima a demanda apresentada e estabelecer relação de confiança, compromisso e vínculo), clínica ampliada compartilhada (considerar a singularidade do sujeito no adoecimento e sofrimento e a complexidade do processo saúde doença) e a defesa dos direitos dos usuários (conhecer os direitos garantidos por lei, facilitar a divulgação e assegurar o cumprimento).

Durante a abertura da atividade de coleta de dados, o objetivo do grupo focal foi explanado de forma clara e apresentadas algumas regras básicas para o momento (falar uma pessoa de cada vez, dizer o que pensa, manter a atenção e discurso no tema, evitar o domínio das falas) (Trad, 2009). A ordem de introdução das questões teve início com a pergunta motivadora: Você poderia dizer o que entende por atendimento humanizado ou humanização da Odontologia? Sequencialmente a conversa foi conduzida por um roteiro norteador dividido em cinco sessões: 1) captar a percepção da humanização de cada participante; 2) entendendo a humanização na Faculdade de Odontologia a partir do acolhimento; 3) clínica ampliada durante o atendimento; 4) intersecção que os estudantes faziam entre a defesa dos direitos dos usuários e a Política Nacional de Humanização; 5) possíveis estratégias para alcançar a humanização na Faculdade de Odontologia.

Foi utilizada a estratégia de saturação das falas (quando não foram identificados novos dados e os dados encontrados são satisfatórios), para encerramento do grupo focal (Minayo, 2017). As falas foram validadas junto aos participantes por meio de uma síntese do conteúdo, apresentada pelo mediador, encerrando-se o grupo focal.

As falas foram gravadas em áudio e a transcrição ocorreu sem a identificação dos participantes, redigida no formato texto e utilizados códigos para identificação (por exemplo $\mathrm{E}_{1}, \mathrm{E}_{2}$ ). $\mathrm{O}$ material transcrito foi submetido a leituras exaustivas para uma compreensão mais aperfeiçoada. Os achados foram interpretados segundo a análise de conteúdo, proposta por Graneheim e Lundman (2004). Seguindo esta orientação metodológica, inicialmente foram identificadas no texto as unidades de significado representadas nas falas. Foi extraído de cada unidade de significado, a sua essência, obtendo-se a unidade de 
significado condensada. Em seguida, foi realizada a interpretação, criando-se com isto as categorias de análise, posteriormente agrupadas em temas.

As narrativas foram analisadas com base no Interacionismo Simbólico, que busca compreender a relação dos grupos sociais com a conduta humana em sua relação cotidiana. Esta reinterpretação representa a forma de como o Interacionismo Simbólico, enxerga a sociedade humana e sua conduta através da percepção do mundo. Baseia-se na realidade social com o outro, atribuindo os significados às suas experiências, que nos indica uma abordagem para o estudo e compreensão da vida e ação humana. Assim, considera que o indivíduo interage com o meio do qual emerge, sendo ator e reator, inserido na sociedade composta de culturas que integram valores e expectativas (Blumer, 1969; Carter \& Fuller, 2015). Para Blumer (1969), cada indivíduo constrói uma percepção do mundo baseada na realidade social desenvolvida através da interação com o meio, atribuindo significados às suas experiências.

A pesquisa foi aprovada pelo Comitê de Ética em Pesquisa (CAAE 73913217.4.0000.5149). Os participantes da pesquisa assinaram o Termo de Consentimento Livre e Esclarecido, sendo que uma via está arquivada com o pesquisador.

\section{Resultados e Discussão}

Participaram desta pesquisa para compor o grupo focal seis estudantes, de diferentes faixas etárias e períodos, tendo a duração de 52 minutos. Em relação ao período, os participantes estavam entre o primeiro e oitavo período do curso de Odontologia. Dois participantes estavam nos períodos iniciais, tendo experenciado visitas na Unidade Básica de Saúde e quatro estudantes estavam nos períodos com vivência clínica e maior contato com o paciente.

Ao ler as narrativas, podemos sugerir que as relações sociais podem ressignificar o sentido de uma palavra, tal como as dimensões teóricas e interpretativas. A percepção da humanização entre os atores sociais do estudo despertou uma reflexão a respeito das questões fundamentais das práticas humanizadas no ensino. A análise revelou que a percepção da humanização vai desde a empatia à perda gradual do olhar humanizado ao longo da formação, devido as práticas do ensino. Os achados serão apresentados com as categorias e os temas que emergiram a partir delas. Para melhor exemplificar, as falas serão apresentadas dentro de cada tema, evidenciando seus aspectos mais relevantes (Tabelas de 1- 3).

\section{- Percepção da humanização}

A Tabela 1 apresenta as falas que representam a percepção da humanização na vivência da reflexão pessoal sobre as experiências de vida e vivência experenciada na Faculdade de Odontologia (Tabela 1). 
Tabela 1 - Falas relacionadas ao tema "Percepção da Humanização."

\section{CATEGORIAS} Empatia

\section{FALAS DOS SUJEITOS}

"A gente o vê (paciente) como pessoa então é o melhor atendimento para ele, entendê-lo como indivíduo dentro do contexto dele ..." $\left(E_{1}\right)$

"Eu acho que humanização é uma questão também de você não ser somente profissional, né? É ter empatia também, é você atuar como um ser humano. " $\left(E_{3}\right)$

"[...]é importante a gente se ver como um paciente também na hora que ele chega. Eu acho que a gente se imaginar no lugar dele mudamos o jeito de agir[...] gente tem que olhar a pessoa como um todo." $\left(E_{5}\right)$

Ouvir o paciente

"[...]ter essa relação profissional-paciente[...] ]entender a essência do paciente[...] saber indicar, se está precisando de alguma outra coisa[...] Jer um tratamento geral, não só na demanda que ele está precisando naquele momento." $\left(E_{4}\right)$

"[...]chegar e conversar um pouquinho, entender mais sobre o paciente, o que que ele tem, se ele faz uso de algum tipo de medicamento, exatamente, que tem alguma alergia, alguma coisa. " $\left(E_{5}\right)$

Fonte: Dados da pesquisa (2017).

A partir da interação do estudante no atendimento clínico, buscou-se apreender as concepções ou relações estabelecidas e medidas na vivência cotidiana de um atendimento humanizado na Faculdade de Odontologia. Desta maneira, os estudantes percebem a necessidade de acolher o paciente em todas as etapas do atendimento, ressaltando que o fenômeno estudado é uma engrenagem para as relações sociais na prática clínica. As falas mostram que a percepção social da humanização e interação entre os atores sociais encontra-se associada à concepção humanística (empatia e ouvir o paciente). Podemos dizer, que esses elementos conversam entre si, a partir do modelo de relações simbólicas e de significados sustentados a partir de um processo de ação com o mundo social. Este é composto por características culturais e de estruturas sociais, institucionais ou não, que fundamentam e guiam o comportamento daqueles que fazem parte do mundo (Souza; Hokama \& Hokama, 2020).

A percepção da humanização para os estudantes, revelou que a empatia foi considerada essencial para o atendimento humanizado. Assim, ressaltaram a capacidade de colocar-se no lugar do outro, compreendendo os sentimentos e emoções, como "Eu acho que a gente se imaginar no lugar dele[... ]"; e procurando de forma emocional entender o que o outro sente. A empatia é uma virtude que desencadeia o vínculo na capacidade de compreender um ponto de vista do outro, sua experiência na doença e por meio dessa reflexão sentir se motivado a ajudá-lo (Bark et al.,2018; Moudatsou et al., 2020). Para Stein (2003), a empatia é a vivência originária do outro que se manifesta diante de nós, remete um esforço reflexivo sobre a vivência. Tonar real, esta vivência a possibilidade de aproximação do vivido do outro a partir da efetividade, exigindo do sujeito empático uma conversão do olhar para a sua própria humanidade. A partir das falas, destaca-se a importância da empatia no processo de formação acadêmica proposta na humanização do atendimento como um mecanismo na integralidade do cuidado.

É importante fazer uma reflexão acerca da importância da empatia nas relações sociais. Trata-se de um mecanismo de saber ouvir o outro para conhecer suas necessidades e suas dificuldades, como destacado na fala "[...]entendê-lo como indivíduo dentro do contexto dele...". A conversa inicial é fundamental para o acolhimento desencadear o estabelecimento de vínculo, a capacidade de ouvir e realizar um bom planejamento. Partindo desse entendimento, podemos ressaltar que, nas entrelinhas das falas, destaca-se a alteridade "[...]entender a essência do paciente[...]". Deste modo, alteridade é encontrar novas formas de aprender e saber no (re)conhecimento do outro. É reconhecer que o outro é diferente de você e saber respeitálo (Lévinas, 1980). Esse trecho da fala, faz uma reflexão sobre a habilidade de enxergar o outro como ser único, aceitando a 
condição de existência de outras opiniões, culturas, crenças e saberes, ressaltando que tal virtude não se enquadra em explicações rígidas (Mota, Farias \& Santos, 2012; Bark et al., 2018). A alteridade e empatia, podem ser entendidas como ferramenta auxiliar ao acolhimento do paciente, principalmente acerca da importância da escuta qualificada durante a anamnese e os atendimentos clínicos (Bark et al., 2018; Souza, Hokama \& Hokama, 2020). Estes são uns dos valores importantes para os profissionais da saúde realizarem um atendimento pautado na integralidade do cuidado (Mayernyik \& Oliveira, 2016; Bark et al.,2018).

Trazer a debate o conceito de humanização no atendimento odontológico provoca percepções importantes sobre a evolução técnica da profissão, que foi marcada ao longa da história pela desarmonia entre o tecnicismo e a qualidade da relação com o paciente (Faé et al., 2016; Bark et al.,2018). O ensino da Odontologia ainda é reflexo do modelo Flexneriano, em que a prática clínica tem uma visão biologicista, curativista e individualista (Quairoz \& Dourado, 2009; Grande, Prochnow, Saab \& Pizzatto, 2016). Vivemos em uma sociedade acelerada, onde a reflexão sobre nosso fazer tem sido pouco questionada e torna-se necessária a partir da fala "[...] humanização é uma questão também de você não ser somente profissional, não é?". Como trabalhar essas questões se somos humanos e temos que aprender a humanização? Ser humanizado é algo extra ao ser profissional?

Para Minayo (2006), na área da saúde o termo "humanismo", passou a ser discutido como política, como proposta e como debate por meio do termo humanização. A humanização do setor da saúde significa um movimento instituinte do protagonismo dos sujeitos na valorização da intersubjetividade e do cuidado das relações. Muitas explicações podem ser dadas para melhorar as relações resgatando os valores humanísticos. Fato é que ser humano implica mais do que simplesmente ser, é refletir sobre as formas de agir, do que se é e do que se faz.

Diante de tal percepção, as falas destacaram que ouvir o paciente potencializa as relações da prática profissional. Este ato no sentido do cuidado em saúde está relacionado ao conceito de humanização, no reconhecimento do outro. Acolher é uma prática fundamental nos serviços de saúde, que vem contribuindo positivamente para a mudança no modelo assistencial centrado não mais na doença, mas na integralidade do indivíduo, sendo este um elemento fundamental para a humanização da assistência em saúde (Nora \& Jundes, 2013; Carvajal et al., 2019). A PNH, tem como uma de suas diretrizes o acolhimento, que é o momento do estabelecimento de confiança, compromisso e vínculo entre profissional-paciente, a partir de uma escuta qualificada e organização das prioridades. Esta é uma ação que deve ocorrer em todos os locais e momentos do serviço de saúde desde a chegada até à saída do paciente (Brasil, 2013a). A escuta qualificada possibilita reconhecer a legítima demanda do paciente, favorecendo a construção da relação de confiança e compromisso entre profissional e serviço.

O acolhimento é o modo de operar os processos de trabalho em saúde de forma a atender a todos que procuram o serviços de saúde, ouvindo seus pedidos e assumindo no serviço uma postura de acolher (Brasil, 2006). Na Faculdade de Odontologia é realizado um trabalho de escuta inicial através de um projeto de extensão para dar respostas mais adequadas aos usuários. Ou seja, prestar um atendimento com resolutividade e orientação, quando for o caso. Neste caso o acolhimento ainda está aquém de acolher, pois apresenta uma característica de triagem que é uma separação e seleção realizados por estudantes de Odontologia que não caracteriza uma atitude de inclusão. O trabalho realizado não possibilita a priorização do acolhimento, a construção de vínculo, a garantia do acesso com responsabilização e a resolutividade nos serviços (Brasil, 2006).

É preciso uma abordagem integral que envolva desde o acolhimento aos aspectos biológicos, psicológicos e sociais (Guerra, Bertoz, Fajardo \& Alves Rezende, 2015; Mayernyik \& Oliveira, 2016). Os estudantes provocaram uma reflexão na conduta das práticas clínicas em Odontologia, mostrando que a humanização do atendimento é um desafio, indo além dos conhecimentos, reconhecidos por eles como "científicos". Através da interação com o meio a compreensão dos significados observados, destacamos as questões subjetivas acerca de como os estudantes de maneira corriqueira em seu cotidiano 
perceberam o significado simbólico atribuído às práticas da humanização. A percepção com origem nos sentidos da humanização foi resinificada pelas relações sociais.

\section{- Humanização e ensino}

A Tabela 2 expõem as falas que representam a percepção da humanização na Faculdade de Odontologia, experenciada durante o percurso da formação a partir do acolhimento e da clínica ampliada durante o atendimento e contato com o paciente (Tabela 2).

Tabela 2 - Falas relacionadas a percepção do tema "Humanização e ensino".

\section{CATEGORIAS} Paciente objeto de estudo

\section{FALAS DOS SUJEITOS}

"'...] gente tem uma matéria específica[...] gente recebe o paciente[...]vai fazer esta coroa aqui e esquece do resto." $\left(E_{3}\right)$

"Tem professor que já chega e não dá nem bom dia ao paciente[...]têm outros que perguntam como está [...] Eu percebi que isso influencia demais na forma de agirmos. " $\left(E_{2}\right)$

'[...] ]o paciente é induzido a fazer um tratamento[... ]ele não sabe das opções[...]Tem que trocar a restauração de um paciente, mas ele nem sabe o porquê. " $\left(E_{5}\right)$

\footnotetext{
Metas a cumprir

"Tem uns que chegam e falam: você tem que fazer isso[...] ]se não fizer você não será aprovado na disciplina. Então, você fica meio paranoico." $\left(E_{1}\right)$

"[...]Ele queria só colar um dente que tinha soltado e fizemos uma peça num outro dente[...]E o professor não deixava. [...] É isso que você vai fazer. " $\left(E_{3}\right)$

"Tem um projeto aqui que é tão corrido. O projeto não tem anamnese, você já pega o paciente e faz, já termina, já pega outro." ( $\left(E_{4}\right)$
}

Fonte: Dados da pesquisa (2017).

Observa-se nas falas que há uma dificuldade do professor e do estudante em conciliar a necessidade do paciente e o conteúdo acadêmico previsto, desvelando um conflito e um possível limite no atendimento. A perspectiva do estudante reflete que há uma dificuldade em desempenhar a humanização no processo de formação, porque o professor na prática do ensino clínico tem que seguir o conteúdo previsto para disciplina e o estudante tem que seguir protocolos de atendimento. A partir das narrativas sugere-se que a preocupação durante os atendimentos clínicos não é atender o outro na integralidade, e sim seguir e terminar todas as etapas do tratamento previstos para cada especialidade, como destaca-se na fala "[...]o paciente é induzido a fazer um tratamento[...] ]ele não sabe das opções[...]Tem que trocar a restauração de um paciente, mas ele nem sabe o porquê. ". A vivência mostra que a formação do cirurgião-dentista ainda é voltada para o tecnicismo, uma reprodução da prática curativa, no qual há uma certa dificuldade em trabalhar a integralidade do cuidado. Nesse contexto, destaca-se que os cursos de Odontologia têm um grande desafio no processo de formação que vai além do caráter tecnicista, agregando ao ensino regular, aspectos que promovam uma educação humanística, crítica e reflexiva, como que possam colaborar na construção da autonomia, de cidadania e do saber (Saliba, Moimaz, Prado \& Garbin, 2012).

A PNH, no âmbito dos processos de formação em saúde, parte de uma escolha ético-política relativa a seus princípios e diretrizes. Ambos afirmam a impossibilidade de dissociar a gestão da atenção e o cuidado; e de produzir saúde, a não ser transversalizando as práticas e saberes. A prática do ensino para a formação do cirurgião-dentista tem reproduzido a fragmentação dos saberes e práticas em saúde, o que pode desencadear no estudante a perda desse olhar humanizado (Guedes; Pitombo \& de Barros, 2009; Faé et al., 2016; Martins \& Luzio, 2017). O processo de desumanização torna-se uma realidade, 
na prática clínica, quando o professor dita ao aluno que a não realização do procedimento acarretará prejuízo ao seu aprendizado ou mesmo, comprometerá sua aprovação. A avaliação não ocorre de forma processual, levando em conta a conduta clínica ou o planejamento integral do caso. O estudante é vítima do processo de avaliação fragmentada. Assim, há uma objetificação do paciente, devido à necessidade de cumprimento de metas. Para Nuto et al. (2006), a avaliação centrada na produção de uma nota e não pelo desenvolvimento da construção do saber, impede o estudante de enxergar o paciente além da "boca".

Na percepção do estudante, uma das questões problemáticas para o ensino é que a postura do professor influencia os processos de formação, sendo este um ponto determinante para a prática clínica. $\mathrm{O}$ autoritarismo presente na relação professorestudante gera baixa-autoestima no processo ensino-aprendizagem, dificultando as relações afetivas consigo mesmo, com colegas, com pacientes e com os próprios docentes. A reprodução do autoritarismo é muito latente na prática odontológica (Motta; Santos; Magalhães, 2012; Soares \& Ribeiro, 2020). Infelizmente, o ensino na área da saúde ainda é ditado pelas relações pedagógicas, nas quais o professor é considerado o detentor do saber, na figura de autoridade máxima e os estudantes seguem sem questionar o que lhe foi proposto, repetindo o círculo vicioso do ensino exclusivamente técnico-científico (Nora \& Jungues, 2013; Grade, Prochnow, Saab \& Pizzatto, 2016; Soares \& Ribeiro, 2020). Para Freire (2020), a educação deve estar a serviço da humanização das pessoas, já que é uma forma de intervenção no mundo.

A partir das falas, podemos sugerir que um dos maiores desafios apresentados, é o de construir currículos pedagógicos arraigados na humanização. Projetos pedagógicos que contemplem as DCN e a integração curricular, devem enfatizar a integralidade dos conteúdos técnicos e humanísticos, durante as atividades clínicas, e ao mesmo tempo, conhecer e teorizar sobre as dificuldades na relação interpessoal (Saliba, Moimaz, Prado \& Garbin, 2012; Brasil, 2021). A integralização do ensino-serviço proporciona aos egressos uma formação generalista para atuar em todos os níveis de atenção em saúde. Porém, ao longo do curso, os estudantes vão perdendo essa sensibilidade, devido à fragmentação dos atendimentos. A partir das leituras exaustivas das falas observou-se que os estudantes dos períodos iniciais demostraram mais sensibilidade para qualificação de uma escuta com uma postura acolhedora "[...]chegar e conversar um pouquinho, entender mais sobre o paciente[... $]^{\prime \prime}$. Enquanto que os que os estudantes dos últimos períodos destacaram a questão da perda dessa sensibilidade de dar respostas mais adequadas aos usuários (Brasil, 2006). Pode-se dizer que a necessidade de cumprir metas no decorrer do curso para trabalhar os conteúdos programados nas disciplinas, representada no trecho da fala " $[$.... você já pega o paciente e faz, já termina, já pega outro. ", pode desencadear o não estabelecimento de vínculo durante os atendimentos, tornado distante essa aproximação entre estudante-paciente.

Praticar a humanização no ensino é uma tarefa difícil, que requer mudanças em todos os níveis, desde a gestão da instituição, até os estudantes, os professores e os funcionários. Esse processo de mudança demanda tempo e colaboração de todos. Não se promove humanização sem uma gestão de saúde qualificada (Brasil, 2013a). Embora, não sejam explícitas as questões do comportamento que envolvem humanização e ensino, as (entre)linhas das falas remeteram à desumanização ao longo da formação. Com a compreensão dos significados observados, destacamos as questões subjetivas acerca de como os estudantes percebem a humanização e ensino. As metas a cumprir são percebidas como questões de grande impacto para um atendimento humanizado. Para eles, a vivência das práticas clínicas de ensino é representada pelos professores como fontes de sobrecarga emocional.

\section{- Direito dos usuários}

A Tabela 3 expressa as falas que representam a percepção da humanização frente defesa dos direitos dos usuários e a Política Nacional de Humanização, experenciada na Faculdade de Odontologia durante o percurso da formação (Tabela 3). 
Tabela 3 - Falas relacionadas a percepção do tema "Direito dos Usuários"

CATEGORIAS

Favor por ser atendido

\section{FALAS DOS SUJEITOS}

"Eles acham que estamos dando, que não é um direito deles, tanto é que agradecem muito." $\left(E_{1}\right)$

"Ás vezes não se sentem confortáveis recebendo o tratamento de algum aluno por uma questão específica, ou professor. Ele tem que saber que ele tem o direito de ser atendido por outra pessoa." $\left(E_{6}\right)$

'[...] o aluno trata como se estivesse fazendo um favor, e ele também acha que é um favor. Ele não tem muita noção de que tem direito." $\left(E_{5}\right)$

\section{Falta de informação}

"[...] Jos pacientes que vêm depois dessa triagem ficam perdidos. E muitos vêm e não sabem, por exemplo[...] que a coroa tem que ser paga, valor do trabalho do laboratório[...]" $]^{\prime \prime}\left(E_{2}\right)$

"Falta muita informação para a faculdade e para o posto também. Tem posto que não sabe que tem Sistema de Regulação. Tem paciente que chega com papel, e na verdade o encaminhamento é pelo computador." $\left(E_{4}\right)$

Fonte: Dados da pesquisa (2017).

Através das narrativas observa-se a falta de entendimento sobre o direito dos usuários ao acesso aos serviços de saúde ofertados pelo SUS, tanto para os estudantes quanto para os pacientes. Há uma visão distorcida de que o estudante presta um favor aos usuários por atendê-los e alguns estudantes acreditam, de fato, que é um favor, como destacado na fala "[...] $o$ aluno trata como se estivesse fazendo um favor, e ele também acha que é um favor. Ele não tem muita noção de que tem direito." . Não seria o inverso? Os pacientes consentem ser atendidos por não profissionais, contribuindo com seu aprendizado.

O serviço prestado está vinculado à garantia do Direito à Saúde preconizada no SUS. O pagamento não é realizado diretamente pelo paciente, o valor é repassado sobre a forma de tributos e impostos. O financiamento do SUS está previsto na Constituição e teve sua regulamentação nas Leis Orgânicas da Saúde, as quais, reúnem as leis federais 8.080 e 8.142, de 1990 (Brasil, 2013b). Os financiamentos dos serviços de saúde prestados nas clínicas da Faculdade de Odontologia são de responsabilidade da gestão municipal, sendo o repasse realizado à instituição de acordo com os procedimentos realizados. Os pacientes atendidos são encaminhados pelo sistema regionalizado e hierarquizado de referência e contrarreferência do SUS, e o trabalho desenvolvido a partir de uma equipe interprofissional (Souza et al., 2015).

Segundo Fortes (2004), a humanização possibilita a transformação cultural da gestão e das práticas desenvolvidas nas instituições de ensino superior, imprimindo uma postura ética de respeito pelo outro, o usuário compreendido como um cidadão a ser acolhido, e não meramente como um consumidor de serviço se saúde (Brasil, 2004). A PNH reafirma que os usuários têm seus direitos garantidos por lei, sendo que os serviços e profissionais de saúde devem incentivar o conhecimento desses direitos e assegurar que eles sejam cumpridos em todas as fases do cuidado, desde a sua chegada até sua alta. Cabe a ele o direito a ser informado sobre sua saúde e conduta a ser tomada pelo profissional, assim como decidir sobre compartilhar ou não sua dor e alegria (Brasil, 2013a). Acredita-se que fragilidade da mobilização social decorre do pouco conhecimento do paciente em relação aos seus direitos e deveres no contexto da saúde. Isso revela a falta de clareza e a necessidade de ações educativas para despertar a consciência em comunidade (Castro, Almeida, Silva \& Goulart, 2019). É preciso compartilhar direitos e deveres dos usuários por meio de outro direito fundamental, que é o da informação, mediado pelos profissionais da saúde. Neste sentido, o Ministério da Saúde elaborou cartilhas, a partir dos seis princípios básicos de cidadania, abordando os direitos dos usuários de saúde (Backes et al., 2009; Gatto Junior et al., 2012). Todo indivíduo deve dispor de uma rede de atenção à saúde, composta por um conjunto de serviços e equipamentos de saúde que se organizam para a garantia da prevenção, promoção, proteção, tratamento e recuperação da saúde. 
As falas dos estudantes também apontaram problemas relacionados ao processo organizacional da Faculdade e de encaminhamento da Unidade Básica de Saúde para o atendimento. Os problemas destacados "Falta muita informação para a faculdade e para o posto também. Tem posto que não sabe que tem Sistema de Regulação", estão relacionados com a falta de informação sobre os atendimentos, organização da triagem, falta de conhecimento do profissional sobre o sistema de regulação das consultas e a burocracia para os atendimentos (Souza et al., 2015). Podemos sugerir que estes fatores podem influenciar na desumanização do atendimento, pois falta diálogo entre os profissionais e os pacientes, e entre os profissionais e a administração. Isto implica na não realização da gestão participativa no serviço de saúde da Faculdade de Odontologia, o que pode impactar negatividade a humanização dos serviços de saúde. Para Guimarães \& Mello (2017); o encaminhamento entre as clínicas de atendimento obedece às necessidades da disciplina e acontecem de forma pouco sistematizada. Assim, o acompanhamento do paciente, ao longo do tratamento, muitas vezes também é descrito como um problema, pois se o paciente é encaminhado para outra clínica, o professor e o estudante não têm conhecimento do tratamento realizado.

Não, basta em outras palavras, garantir o acesso e/ou direito ao atendimento no sistema público de saúde e nas instituições de ensino superior conveniadas. Muito além de possibilitar o acesso, é preciso criar estratégias de integralização do ensino-serviço em saúde. Este é entendido como trabalho coletivo, pactuado e integrado entre instituição de ensino superior, por meio de professores, estudantes, funcionários e serviços de saúde, incluindo gestores e trabalhadores. Assim, a prática clínica que acontece em seus ambientes, deve estar de acordo com a qualidade da atenção à saúde individual e coletiva, bem como a qualidade de formação profissional, e satisfação da população e dos trabalhadores em saúde (Faé et al., 2016; Guimarães \& Mello, 2017). É desejável que a universidade e o serviço ampliem o olhar do estudante, possibilitando entender todo o funcionamento da rede de serviços de saúde, integrando-o não apenas ao cenário da saúde bucal, mas na integralidade do cuidado (Faé et al., 2016). É preciso trabalhar o direito dos usuários em conjunto com a humanização considerando a importância das interações sócias. A reflexão acerca destes temas permite que os atores sociais se tornem engajados e comprometidos, por meio de seus direitos e deveres, na luta pela transformação da sociedade.

\section{Considerações Finais}

As universidades são chamadas para exercer um papel importante no processo de formação do ser humano, do profissional cidadão comprometido com as responsabilidades sociais com conhecimentos científicos, críticos, éticos, humanísticos e reflexivos. É importante, nos cursos de graduação em Odontologia, que o ensino da humanização seja contemplado de forma transversal, para fazer as aproximações teóricas, com uma visão que extrapole a compreensão do ser humano de forma coletiva e individual no processo da integralidade do cuidado.

A humanização em saúde, muitas vezes é de difícil compreensão, referindo-se a questões da prática clínica, ficando mais palpável aos estudantes quando estimulados a refletir sobre a percepção da humanização nas relações sociais. Nas práticas de ensino, a humanização em saúde pode pautar-se na Política Nacional de Humanização, para essa aproximação teórica fazer sentido. Os princípios da humanização buscam transformar as relações de trabalho, a partir da ampliação do grau de contato com uma escuta qualificada entre os atores sociais, tirando-os das relações de hierarquização.

Dessa forma, nota-se a deficiência da humanização no cuidado do paciente na instituição de ensino superior. Daí que, a construção da percepção da humanização apontou a necessidade de melhoria contínua, entre teoria e prática, contribuindo com os movimentos de mudança a partir do ensino da humanização em saúde durante o processo de formação do cirurgiãodentista. Por fim, os achados apontaram os limites a serem rompidos pela humanização e o desafio de que a estratégia de integralidade do atendimento possa ser a tradução de um novo agir na formação, para consolidar uma atenção à saúde mais humana. 
Acreditamos que este estudo oportuniza a produção de outras pesquisas que abranjam o ensino da humanização em saúde, como a busca do desenvolvimento da formação do cirurgião-dentista, de modo que o ambiente da sala de aula e dos atendimentos clínicos sejam pautados no exemplo e empenho conjunto para uma prática significativa sobre o tema.

\section{Agradecimentos}

O presente projeto foi desenvolvido com apoio da Fundação de Amparo à Pesquisa do Estado de Minas Gerais (FAPEMIG) através da concessão de bolsa de estudo de Mestrado/Auxílio a Projeto de pesquisa, CAAE 73913217.4.0000.5149.

\section{Referências}

Brasil. Ministério da Educação. Conselho Nacional de Educação / Câmara de Educação. Resolução CNE/CES $n^{\circ} 3 / 2002$, de 19 de fevereiro de 2002. Institui Diretrizes Curriculares Nacionais do Curso de Graduação em Odontologia.

Brasil. Ministério da Saúde. HumanizaSUS: Política Nacional de Humanização: a humanização como eixo norteador das práticas de atenção e gestão em todas as instâncias do SUS. Ministério da Saúde, 2004. 19p.

Brasil. Ministério da Saúde. Secretaria de Atenção à Saúde. Núcleo Técnico da Política Nacional de Humanização. Acolhimento nas práticas de produção de saúde. Brasília: Ministério da Saúde; 2006.

Brasil. Ministério da Saúde. Glossário temático: promoção da saúde. Ministério da Saúde, 2012. p. 23.

Brasil. Ministério da Saúde. Política Nacional de Humanização - PNH. 2013a.

Brasil. Ministério da Saúde. Financiamento público de saúde / Ministério da Saúde, Organização Pan-Americana da Saúde. Ministério da Saúde, 2013b. 124p.

Brasil. Ministério da Educação. Conselho Nacional de Educação / Câmara de Educação. Resolução CNE/CES $n^{\circ} 3$, de 21 de junho de 2021 Institui as Diretrizes Curriculares Nacionais do curso de graduação em Odontologia e dá outras providências.

Backes, D. S., Santos, K., M., Ribeiro, L. R. A. C., Crespo Drago, L., Klock, P. \& Lorenzini Erdmann, (2009). A. O que os usuários pensam e falam do Sistema Único de Saúde? Uma análise dos significados à luz da carta dos direitos dos usuários. Ciência \& Saúde Coletiva. 14(3):903-910.

Barck, M. M., Posanski, M., Oliveira, K. V. de. Brancher, J. A., Kriger, L. \& Gabardo, M. C. L. (2018). Alteridade e empatia: virtudes essenciais para a formação do cirurgião-dentista, Revista da ABENO. 18(2):104-113.

Benevides, R. \& Passos, E. (2005). Humanização na saúde: um novo modismo? Interface - Comunic, Saúde, Educ. 9(17):389-406.

Blumer, H. Symbolic Interactionism: Perspective and Method. Berkeley: University of California Press, 1969. 219p.

Carter, M. J. \& Fuller, C. (2015). Symbolic interactionism. Sociopedia.isa. 1:1-17.

Carvajal, M., López, S., Sarabia-Alvarez, P., Fontealba, J., Padilla, M., Sumi, J., \& Díaz-Narváez, V. P. (2019). Empathy levels of dental facult and students: a survey study at na academic dental instituion in Chile. Jounal of Dental Education. 83(10):1134-1141.

Castro, B. C. S., Almeida, L. G., Silva, R. C. \& Goulart, B. F. (2019). Derechos y deberes de los usuarios del Sistema Único de Salud: relato de experiência. REFACS (online). 7(1):111-118.

Emmi, D. T., Silva, D. M. C. \& Barroso, R. F. F. (2018). Integrated teaching to service experience in Health professional education: perception of dentistry students and graduates. Interface (Botucatu). 22(64):223-236.

Faé, J. M., Silva-Junior, M. F., Carvalho, R. B. de. Esposti, C. D. D. \& Pacheco, K. T. S. (2016). A integração ensino-serviço em Odontologia no Brasil. Rev. ABENO [online]. 16(3):07-18.

Fortes, P. A. C. (2004). Ética, direitos dos usuários e políticas de humanização da atenção à saúde. Saúde Soc. 3(3):30-35.

Forte, F. D. S., Pessoa, T. R. R. F., Freitas, C. H. S., Pereira, C. A. L. \& Junior, P. M. C. (2015). Reorientação na formação de cirurgiões-dentistas: o olhar dos preceptores sobre estágios supervisionados no Sistema Único de Saúde (SUS). Interface Comunicação Saúde Educação. 19(1):831-43.

Freire, Paulo. Pedagogia do oprimido. (73a ed.), ed. Paz e Terra, 2020. 256p.

Fuente-Martos, C. De La, M., rojas-Amezcua, M. R., gómez-Espejo, P., Lara-aguayo, E., Morán-Fernandez, E., Aguilar-Alonso, E. (2018). Humanization in healthcare arises from the need for a holistic approach to illness. Medicina Intensiva. 42(2):99-109.

Gatto Junior, J. R., Santo, A. S. dos. Brito, E. S. de. \& Freitas, I. M. (2012). O Direito Humano à Saúde no Brasil e a Carta dos Direitos dos Usuários da Saúde. Brazilian Journal of Forensic Sciences, Medical Law and Bioethics 1(2):47-64.

Guedes, C. R.; Pitombo, L. B. \& De barros, M. E. B. (2009). Os processos de formação na política nacional de humanização: A experiência de um curso para gestores e trabalhadores da atenção básica em saúde. Physis. 19(4):1087-1109. 
Guerra, C. T., Bertoz, A. P. de M., Fajardo, R. S., \& Alves Rezende, M. C. R. (2015). Reflexões sobre o conceito de atendimento humanizado em Odontologia. Archives of health investigation, 3(6):31-36.

Guimarães, F. A. F. \& Mello, A. L. S. F. (2017). Prestação de serviços odontológicos em instituições federais públicas de ensino superior e a integração com a rede de atenção à saúde. Rev ABENO. 17(3):10-20.

Grade, I. M. P.; Prochnow, R., Saab, R. \& Pizzatto, E. (2016). Desafios na formação do Cirurgião-Dentista para o SUS. Rev. ABENO [online]. 16(3):02-06.

González, F. E. (2020). Reflexões sobre alguns conceitos da pesquisa qualitativa. Revista Pesquisa Qualitativa.8(17):155-183.

Graneheim, U. \& Lundman, B. (2004). Qualitative content analysis in nursing research: concepts, procedures and measures to achieve trustworthiness. Nurse Educ Today. 24:105-112.

Lage, R. H., Alemeida, S. K. T. T., Vasconcelos, G. A. N., Assaf, A. V. \& Robles, F. R. P. (2017). Ensino e Aprendizagem em Odontologia: Análise de Sujeitos e Práticas. Revista Brasileira de Educação Médica. 41(1):22-29.

Lévinas, E. Totalidade e infinito. Trad. de José Pinto Ribeiro. (70a ed.), 1980. p. 180

Martins, C.P. \& LUZIO, C. A. (2017). HumanizaSUS policy: anchoring a ship in space. Interface (Botucatu). 2017; 21(60):13-22.

Mayernyik, M. A. \& Oliveira, F. A. G. (2016). O cuidado empático: contribuições para a ética e sua interface com a educação moral na formação em saúde. Revista Brasileira de Educação Médica. 140(1):11-20.

Minayo, M. C. S. (2006). Prefácio. In: DESLANDES, S. F. Humanização dos cuidados em saúde: conceitos, dilemas e práticas [online]. FIOCRUZ. p.23-30.

Minayo, M. C. S. (2013). O desafio do conhecimento: Pesquisa qualitativa em saúde. Hucitec. 14.ed. 407p.

Minayo, M. C. (2017). Amostragem e saturação em pesquisa qualitativa: consensos e controvérsias. Revista Pesquisa Qualitativa. 5(7):01-12.

Moreira, M. A. D. M., Lustosa, A. M., Dutra, F, Barros, E. O., Batista, J. B. V. \& Duarte, M. C. S. (2015). Public humanization policies: integrative literature review. Ciência \& Saúde Coletiva. 20(10):3231-3242.

Mota, L. de Q., Farias, D. B. L. M., \& Santos, T. A. dos. (2016). Humanização no atendimento odontológico: acolhimento da subjetividade dos pacientes atendidos por alunos de graduação em Odontologia. Arquivos Em Odontologia, 48(3):151-158

Moudatsou, M., Stavropoulou, A., Philalithis, A., \& Koukouli, S. (2020). The Role of Empathy in Health and Social Care Professionals. Healthcare. Basel, Switzerland. 8(1):1-9.

Nora, C. R. D. \& Junges, J. R. (2013). Política de humanização na atenção básica: revisão sistemática. Rev. Saúde Pública. 47(6):1186-1200.

Nuto, S. A. S., Noro, L. R. A., Cavalsina, P. G., Costa, I. C. C. \& Roncalli, A. G. C. O. (2006). O processo ensino-aprendizagem e suas consequências na relação professor-aluno-paciente. Ciência \& Saúde Coletiva. 11(1):89-96.

Puplaksis, N. V., Silva, M. M. P., Nobile, R. \& Ramos, D. L. P. (2010). Disciplina de bioética na Faculdade de Odontologia da Universidade de São Paulo. Rev. Latinoamericana de Bioética. 10(2):68-75.

Queiroz, M. G. \& Dourado, L. F. (2009). O ensino da odontologia no Brasil: uma leitura com base nas recomendações e nos encontros internacionais da década de 1960. História, Ciências, Saúde. 16(4):1011-1026.

Rios, I. C. Humanização: a essência da ação técnica e ética nas práticas de saúde. Rev. Bras. Educ. Med. 33(2):253-261.

Saliba, N. A., Moimaz, S. A. S., Prado, R. L \& Garbin, C. A. S. Percepção do cirurgião-dentista sobre formação profissional e dificuldades de inserção no mercado de trabalho. Rev. Odontol. UNESP. 41(5):297-304.

Scalioni, F. A. R., Alves, R. T., Matos, C. L. B. \& Ribeiro, R. A. (2008). Humanização na Odontologia: a Experiência da Disciplina Odontopediatria II do Curso de Graduação em Odontologia da UFJF. Pesqui. Bras. Odontopediatria Clín. Integr. 8(2):185-190.

Soares Silva, A. de S., \& Ribeiro, M. L. (2020). Relação professor-estudante no ensino superior: uma revisão de literatura. Educação Por Escrito. 11(1):1-10.

Souza, G. C., Lopes, M. L. de S., Roncalli, A. G., Medeiros-Junior, A. \& Clara-Costa, I. do C. (2015). Referência e contra referência em saúde bucal: regulação do acesso aos centros de especialidades odontológicas. Rev. salud pública. 17 (3): 416-428.

Souza, M. K. B., Lima, Y. O. R., Paz, B. M. S., Costa, E. A., Cunha, A. B. O. \& Santos, R. (2019). Potencialidades da técnica de grupo focal para a pesquisa em vigilância sanitária e atenção primária à saúde. Revista Pesquisa Qualitativa. 7(13):57-71.

Souza, L., Hokama, P., Hokama, N. (2020). A empatia como instrumento para a humanização na saúde: concepções para a prática profissional. REVASF. 10(21):148-167.

Souza, V. R., Marziale, M. H., Silva, G. T. \& Nascimento, P. L. (2021). Tradução e validação para a língua portuguesa e avaliação do guia COREQ. Acta Paul Enferm. 34:1-9.

Stein, E. Il problema dell' Empatia. Roma: Edizioni Studium. 2003. 271p.

Sueiras, P., Romano-Betch, V., Vergil-Slagado, A., Hoyos, A., Quintana-Vasrgas, S., Ruddick, W., Castro-Santana, A., Islas-Andrade, S. \& AltamiranoBustamante, N.F. (2017). Today's medical self and the other: Challenges and evolving solutions for enhanced humanization and quality of care. PLoS ONE. 12(7):1-23. 
Research, Society and Development, v. 10, n. 13, e45101320843, 2021

(CC BY 4.0) | ISSN 2525-3409 | DOI: http://dx.doi.org/10.33448/rsd-v10i13.20843

Terra, T. A. M., Brasil, L. O. F., Von Held, G. M. \& Rocha, M. F. (2018). A importância da humanização para a formação médica através de uma análise bibliométrica. Acta Biomedica Brasiliensia. 9(2/):10-23.

Trad, L. A. B. (2009). Grupos focais: conceitos, procedimentos e reflexões baseadas em experiências com o uso da técnica em pesquisas de saúde. Physis Revista de Saúde Coletiva. 19(3):777-796. 